\title{
Model validity and risk of bias in randomised placebo-controlled trials of individualised homeopathic treatment
}

\author{
Robert T. Mathie ${ }^{\mathrm{a}, *}$, Michel Van Wassenhoven ${ }^{\mathrm{b}}$, Jennifer Jacobs ${ }^{\mathrm{c}}$, Menachem Oberbaum ${ }^{\mathrm{d}}$, \\ Joyce Frye $^{\mathrm{e}}$, Raj K. Manchanda ${ }^{\mathrm{f}}$, Helmut Roniger ${ }^{\mathrm{g}}$, Flávio Dantas ${ }^{\mathrm{h}}$, Lynn A. Legg ${ }^{\mathrm{i}}$, \\ Jürgen Clausen $^{\mathrm{j}}$, Sian Moss ${ }^{\mathrm{k}}$, Jonathan R.T. Davidson ${ }^{1}$, Suzanne M. Lloyd ${ }^{\mathrm{m}}$, Ian Ford ${ }^{\mathrm{m}}$, \\ Peter Fisher ${ }^{\mathrm{g}}$ \\ a British Homeopathic Association, Hahnemann House, 29 Park Street West, Luton LU1 3BE, UK \\ ${ }^{\mathrm{b}}$ Formerly, LMHI Research Secretary, Rue Taille Madame 23, B-1450 Chastre, Belgium \\ ' School of Public Health and Community Medicine, University of Washington, Seattle, WA 98195, USA \\ ${ }^{\mathrm{d}}$ Center for Integrative Complementary Medicine, Shaare Zedek Medical Center, Jerusalem, Israel \\ e Formerly, Center for Integrative Medicine, University of Maryland School of Medicine, Baltimore, MD 21201, USA \\ ${ }^{\mathrm{f}}$ Central Council for Research in Homeopathy, Department of AYUSH, Ministry of Health E' Family Welfare, Government of India, New Delhi 110058, India \\ ${ }^{g}$ Royal London Hospital for Integrated Medicine, 60 Great Ormond Street, London WC1N 3HR, UK \\ ${ }^{\mathrm{h}}$ Department of Clinical Medicine, Universidade Federal de Uberlândia, Uberlândia, Brazil \\ i Department of Biomedical Engineering, University of Strathclyde, Glasgow, UK \\ ${ }^{\mathrm{j}}$ Formerly, Karl und Veronica Carstens-Stiftung, Essen, Germany \\ ${ }^{\mathrm{k}}$ Homeopathy Research Institute, London, UK \\ ${ }^{1}$ Department of Psychiatry and Behavioral Sciences, Duke University Medical Center, Durham, NC, USA \\ $\mathrm{m}$ Robertson Centre for Biostatistics, Institute of Health and Wellbeing, University of Glasgow, Glasgow, UK
}

\section{A R T I C L E I N F O}

\section{Article history:}

Received 14 September 2015

Accepted 11 January 2016

Available online 20 January 2016

\section{Keywords:}

Individualised homeopathy

Meta-analysis

Model validity

Randomised placebo-controlled trials

Systematic review

\begin{abstract}
A B S T R A C T
Background: To date, our programme of systematic reviews has assessed randomised controlled trials (RCTs) of individualised homeopathy separately for risk of bias (RoB) and for model validity of homeopathic treatment (MVHT).

Objectives: The purpose of the present paper was to bring together our published RoB and MVHT findings and, using an approach based on GRADE methods, to merge the quality appraisals of these same RCTs, examining the impact on meta-analysis results.

Design: Systematic review with meta-analysis.

Methods: As previously, 31 papers (reporting a total of 32 RCTs) were eligible for systematic review and were the subject of study.

Main outcome measures: For each trial, the separate ratings for RoB and MVHT were merged to obtain a single overall quality designation ('high', 'moderate, "low", 'very low'), based on the GRADE principle of 'downgrading'.

Results: Merging the assessment of MVHT and RoB identified three trials of 'high quality', eight of 'moderate quality', 18 of 'low quality' and three of 'very low quality'. There was no association between a trial's MVHT and its RoB or its direction of treatment effect $(P>0.05)$. The three 'high quality' trials were those already labelled 'reliable evidence' based on RoB, and so no change was found in meta-analysis based on best-quality evidence: a small, statistically significant, effect favouring homeopathy.

Conclusion: Accommodating MVHT in overall quality designation of RCTs has not modified our preexisting conclusion that the medicines prescribed in individualised homeopathy may have small, specific, treatment effects.
\end{abstract}

(C) 2016 Elsevier Ltd. All rights reserved.

\footnotetext{
* Corresponding author. Fax: +44 1582723032.

E-mail address: rmathie@britishhomeopathic.org (R.T. Mathie).
}

\section{Background}

Our programme of systematic reviews of randomised controlled trials (RCTs) in homeopathy is focusing its quality assessment both on internal validity (risk of bias, RoB) and on model validity (MV). ${ }^{1}$ 
Our earlier work on RoB showed that, of 32 eligible RCTs of individualised homeopathy, none was totally free from potential bias, though three comprised 'reliable evidence'. ${ }^{2}$ As regards MV of the same 32 RCTs, 19 were considered acceptable, nine uncertain, and four inadequate. ${ }^{3}$ Sensitivity analysis reflecting the 'reliable evidence' produced cautious support for the hypothesis that the effect of the individualised homeopathic intervention is distinguishable from the same approach using placebos. ${ }^{2}$

The purpose of the present paper is to merge together our previously published RoB and MV findings, ${ }^{2,3}$ and, using an approach based on the GRADE method ${ }^{4}$ to establish an overall quality designation for each of the 32 RCTs and to examine its impact on the sensitivity analysis findings. Inter-relationships between RoB, MV and direction of treatment effect are also explored.

\section{Methods}

\subsection{Inclusion criteria for RCTs}

We previously applied the appraisal methods for RoB and for model validity of homeopathic treatment (MVHT), as described, ${ }^{1,3-5}$ to peer-reviewed papers that reported randomised placebo-controlled trials of individualised homeopathy, published up to the end of 2013. Through formal literature search methods, and after application of defined exclusion criteria, 31 papers (reporting a total of 32 RCTs) were found to be eligible for systematic review. $^{2}$

\subsection{Assessment of model validity of homeopathic treatment}

For each trial, the domains for MVHT assessment are summarised as follows ${ }^{3,5}$ :

Domain I (Rationale): Would a significant body of accredited homeopaths support the rationale for the intervention used in the study?

Domain II (Principles): Is the specific intervention used consistent with homeopathic principles?

Domain III (Practitioner): Does the study have suitably qualified and experienced homeopathic practitioner input?

Domain IV (Outcome measure): Does the main outcome measure reflect the main effect expected of the intervention used?

Domain V(Outcome sensitivity): Is the main outcome measure capable of detecting change?

Domain VI (Follow-up): Is the length of follow-up for the main outcome measure appropriate to detect the intended effect of the intervention?

The overall MVHT classification per trial was assigned as follows ${ }^{3,5}$ :

Acceptable MVHT: acceptable rationale (domain I) and principles (domain II); acceptable outcome measure (domain IV) and sensitivity (domain V); not 'inadequate MVHT' in either of the other two domains (III, VI).

Uncertain MVHT: 'unclear' for at least one of the four key domains (I, II, IV, V); not 'inadequate MVHT' for either of the other domains (III, VI)

Inadequate MVHT: 'inadequate MVHT' for any one or more domains.

\subsection{Assessment of risk of bias}

For each trial, the domains for RoB are summarised as follows ${ }^{6}$. Domain I: sequence generation.

Domain II: allocation concealment used to implement the random sequence.

Domain IIIa: blinding of participants and study personnel.
Domain IIIb: blinding of outcome assessors.

Domain IV: incomplete outcome data.

Domain V: selective outcome reporting.

Domain VI: other sources of bias.

The overall RoB classification per trial was assigned as follows ${ }^{2}$ :

- Low risk of bias overall: low risk of bias for each of the seven domains above (designated reliable evidence).

- Uncertain risk of bias overall: unclear RoB for at least one domain; low RoB for all other domains.

- A trial was designated reliable evidence if the uncertainty in its risk of bias was for one of domains IV, V or VI only (and free of overt bias for each of domains I, II, IIIA and IIIB).

- High risk of bias overall: high RoB for any one or more domains.

\subsection{Merging RoB and MVHT into single overall quality designation}

Our separate ratings for $\mathrm{RoB}^{2}$ and $\mathrm{MVHT}^{3}$ were merged to obtain a single overall designation, based on the GRADE principle of 'downgrading' trials with lesser degrees of quality. ${ }^{4}$ For the current study, a trial was downgraded using the specific approach shown in Table 1.

\subsection{Direction of treatment effect}

For each trial, the 'direction of treatment effect' was described statistically as 'favouring homeopathy' or 'favouring placebo', as per the findings of our previous meta-analysis. ${ }^{2}$ These descriptions reflect, respectively, a mean odds ratio (OR) greater than or less than 1.00; statistical significance at $P \leq 0.05$ was attributed if the $95 \%$ confidence interval $(\mathrm{CI})$ did not overlap the value $\mathrm{OR}=1.00$.

\subsection{Inter-relationship between trial attributes}

We planned to use the Chi-squared $\left(\chi^{2}\right)$ test to compare frequencies of observations, and thus the inter-relationships between RoB and MVHT and direction of treatment effect. Fisher's Exact test was preferred when expected frequency was less than 5 in at least one cell of a given frequency table.

\subsection{Sensitivity analysis}

Sensitivity analysis, using methods corresponding to those in our associated paper, ${ }^{2}$ examined the impact on the pooled OR of trials' overall quality designation.

\section{Results}

\subsection{MVHT overall}

As previously reported, ${ }^{3}$ there were 19 trials with acceptable MVHT, nine with uncertain MVHT, and four with inadequate MVHT (Table 2).

\subsection{RoB overall}

No trials had low RoB. ${ }^{2}$ There were 12 trials with uncertain RoB (three of which were designated 'reliable evidence': study numbers A5, A19 and A20 in Table 2), and 20 with high RoB (Table 2).

\subsection{Overall quality designation (Table 2)}

Each of the three trials assessed as 'reliable evidence'2 had acceptable $\mathrm{MVHT}^{3}$ : these three trials were therefore designated 
Table 1

Method for merging RoB and MVHT into single overall designation of quality.

\begin{tabular}{|c|c|c|c|c|}
\hline \multicolumn{2}{|c|}{ Attribute of quality } & \multirow[b]{2}{*}{$\begin{array}{l}\text { Descriptive criteria for } \\
\text { downgrading }\end{array}$} & \multirow[b]{2}{*}{ Downgrading } & \multirow[b]{2}{*}{$\begin{array}{l}\text { Overall } \\
\text { designation }\end{array}$} \\
\hline RoB & MVHT & & & \\
\hline Low risk & Acceptable & \multirow{2}{*}{ Neither attribute has important flaws } & \multirow{2}{*}{0} & \multirow{2}{*}{ High quality } \\
\hline Uncertain risk $* *$ & Acceptable & & & \\
\hline Uncertain risk & Acceptable & \multirow{2}{*}{$\begin{array}{l}\text { One attribute is 'uncertain'; the other } \\
\text { attribute is 'uncertain' or better }\end{array}$} & \multirow{2}{*}{-1} & \multirow{2}{*}{ Moderate quality } \\
\hline Uncertain risk & Uncertain & & & \\
\hline Uncertain risk & Inadequate & \multirow{3}{*}{ One attribute has important flaws } & \multirow{3}{*}{-2} & \multirow{3}{*}{ Low quality } \\
\hline High risk & Acceptable & & & \\
\hline High risk & Uncertain & & & \\
\hline High risk & Inadequate & Both attributes have important flaws & -3 & Very low quality \\
\hline
\end{tabular}

No trial in the current study was designated 'low risk of bias'-see Section 3.

** Includes those trials designated 'reliable evidence'.

'high quality', and so remain the top-ranked RCTs of individualised homeopathic treatment. Of the other nine trials that had uncertain RoB, eight had acceptable or uncertain MVHT, and one had inadequate MVHT; with appropriate downgrading by quality, these trials were designated respectively as 'moderate quality' $(N=8)$ and 'low quality' $(N=1)$. Thus, 11 RCTs were not importantly deficient in quality overall. Of the remaining 21 RCTs, 18 were designated 'low quality' and three as 'very low quality'.

\subsection{Direction of treatment effect (Table 2)}

Only 22 of the 32 trials had data that were extractable for metaanalysis. $^{2}$ Fifteen of these 22 had a direction of treatment effect favouring homeopathy; seven favoured placebo.

\subsection{Inter-relationship between trial attributes}

\subsubsection{MVHT and risk of bias}

There was no evidence to support an association between MVHT and RoB (Fisher's Exact $P=0.882$ )-Table 3.

\subsubsection{MVHT and direction of treatment effect}

There was no evidence to support an association between a trial's MVHT and its direction of treatment effect (Fisher's Exact $P=0.381$ )-Table 4 .

\subsubsection{Risk of bias and direction of treatment effect}

There was no evidence to support an association between a trial's RoB and its direction of treatment effect (Fisher's Exact $P=0.690$ ) - Table 5 .

\subsection{Sensitivity analysis}

Table 6 shows the effect of removing data by trials' overall quality designation: i.e., removing 11 'low-quality' RCTs, then eight 'moderate-quality' RCTs. The pooled OR showed a small, statistically significant, effect in favour of homeopathy for each set of $\mathrm{N}$ trials, including for the final $N=3 \mathrm{RCTs}$ (those designated 'high quality').

\section{Discussion}

Our study has successfully brought together RoB and MVHT assessments using an approach based on the GRADE system of 'downgrading' lesser-quality trials. Merging together the two quality attributes revealed 11 out of 32 trials with either high or moderate quality overall. Those with 'high quality' are the three RCTs that comprise 'reliable evidence' based on $\mathrm{RoB}^{2}$ and that also possess acceptable MVHT. ${ }^{3}$ The main finding from our prior meta-analysis ${ }^{2}$ has therefore not been modified by accommodating MVHT: there is cautious support for the hypothesis that the effect of the individualised homeopathic intervention is distinguishable from the same approach using placebos.

The trials with 'moderate quality' overall are eight of nine RCTs that comprise uncertain risk of bias. ${ }^{2}$ The MVHT-deficient trial with uncertain risk of bias (study number A25) displayed a direction of treatment effect favouring homeopathy. ${ }^{\text {a }}$ There was no trial that had inadequate MVHT and whose direction of effect favoured placebo, though other MVHT-deficient trials did not contain extractable data for meta-analysis, preventing their quantitative examination.

It is notable that many trials with acceptable MVHT had high RoB. Indeed, high RoB comprised the major proportion of trials in each class of MVHT (Table 3), though no statistically significant inter-relationships were evident. The proportion of trials with a given direction of treatment effect appeared to be little affected by RoB and/or MVHT; the total number of trials is too small, however, to enable definitive conclusions. The absence of such relationships is supported by our sensitivity analysis, which showed a small, significant, treatment effect toward homeopathy irrespective of the quality of trial retained in analysis. To date, therefore, there is no evidence that the MVHT method merely intercepts those trials with evidence against homeopathy, as has been suggested recently. ${ }^{?}$

It remains a matter of concern to homeopathy that two-thirds (21 of 32) RCTs of individualised homeopathic treatment have importantly deficient quality overall. Although RCTs in conventional medicine have not benefitted from a two-attribute appraisal of quality such as ours, systematic reviews that solely examined RoB have frequently expressed concern about the insufficient quan-

\footnotetext{
a Additional sensitivity analysis based on the original authors' selection of 'primary outcome measure' has identified potentially a fourth RCT in the category 'uncertain RoB-reliable evidence': http://www.britishhomeopathic.org/wpcontent/uploads/2015/01/BHA-16-Jan-2015.pdf. That RCT (White, 2003: study number A39 in tabulated material) would then be upgraded in our current rank order classification - see Appendix - as a second trial that is MVHT-deficient and with uncertain risk of bias, displaying a direction of treatment effect favouring homeopathy: its overall designation would be 'low quality' rather than 'very low quality'.
} 
Table 2

Rank order of 32 trials by overall quality designation, and showing direction of treatment effect (from meta-analysis data ${ }^{2}$ ).

\begin{tabular}{|c|c|c|c|c|c|c|c|}
\hline Ref. & First author & Year & Overall RoB & Overall MVHT & Downgrading & Overall designation & Direction of effect \\
\hline A5 & Bell & 2004 & Uncertain $* *$ & Acceptable & 0 & High quality & Homeopathy \\
\hline A19 & Jacobs & 1994 & Uncertain $* *$ & Acceptable & 0 & High quality & *Homeopathy \\
\hline $\mathrm{A} 20$ & Jacobs & 2001 & Uncertain $* *$ & Acceptable & 0 & High quality & Homeopathy \\
\hline A10 & Chapman & 1999 & Uncertain & Acceptable & -1 & Moderate quality & Homeopathy \\
\hline A14 & Frass & 2005 & Uncertain & Acceptable & -1 & Moderate quality & *Homeopathy \\
\hline A23 & Jacobs & $2005 \mathrm{a}$ & Uncertain & Acceptable & -1 & Moderate quality & Placebo \\
\hline A36 & \begin{tabular}{|l|} 
Thompson \\
\end{tabular} & 2005 & Uncertain & Acceptable & -1 & Moderate quality & Homeopathy \\
\hline A41 & Yakir & 2001 & Uncertain & Acceptable & -1 & Moderate quality & Homeopathy \\
\hline A6 & Bonne & 2003 & Uncertain & Uncertain & -1 & Moderate quality & Placebo \\
\hline A11 & de Lange de Klerk & 1994 & Uncertain & Uncertain & -1 & Moderate quality & Homeopathy \\
\hline A35 & Straumsheim & 2000 & Uncertain & Uncertain & -1 & Moderate quality & Placebo \\
\hline A7 & Brien & 2011 & High & Acceptable & -2 & Low quality & Placebo \\
\hline A9 & Cavalcanti & 2003 & High & Acceptable & -2 & Low quality & Homeopathy \\
\hline A13 & Fisher & 2006 & High & Acceptable & -2 & Low quality & Homeopathy \\
\hline A18 & Jacobs & 1993 & High & Acceptable & -2 & Low quality & $-\cdots$ \\
\hline A21 & Jacobs & 2000 & High & Acceptable & -2 & Low quality & $-\cdots$ \\
\hline A22 & Jacobs & $2005 b$ & High & Acceptable & -2 & Low quality & *Homeopathy \\
\hline A24 & Jansen & 1992 & High & Acceptable & -2 & Low quality & $-\cdots$ \\
\hline A31 & Rastogi (a) & 1999 & High & Acceptable & -2 & Low quality & Homeopathy \\
\hline A31 & Rastogi (b) & 1999 & High & Acceptable & -2 & Low quality & Placebo \\
\hline A33 & Siebenwirth & 2009 & High & Acceptable & -2 & Low quality & Placebo \\
\hline A38 & Weatherley-Jones & 2004 & High & Acceptable & -2 & Low quality & Homeopathy \\
\hline A16 & Gaucher & 1994 & High & Uncertain & -2 & Low quality & $---\cdot$ \\
\hline A26 & Katz & 2005 & High & Uncertain & -2 & Low quality & $-\cdots$ \\
\hline A30 & Naudé & 2010 & High & Uncertain & -2 & Low quality & $\begin{array}{ll}--- \\
\end{array}$ \\
\hline A32 & Sajedi & 2008 & High & Uncertain & -2 & Low quality & Placebo \\
\hline A37 & Walach & 1997 & High & Uncertain & -2 & Low quality & --- \\
\hline A40 & Whitmarsh & 1997 & High & Uncertain & -2 & Low quality & Homeopathy \\
\hline $\mathrm{A} 25$ & Kainz & 1996 & Uncertain & Inadequate & -2 & Low quality & Homeopathy \\
\hline $\mathrm{A} 1$ & Andrade & 1991 & High & Inadequate & -3 & Very low quality & $-\cdots$ \\
\hline A34 & \begin{tabular}{|l} 
Steinsbekk \\
\end{tabular} & 2005 & High & Inadequate & -3 & Very low quality & $-\cdots-$ \\
\hline A39 & White & 2003 & High & Inadequate & -3 & Very low quality & $-\cdots$ \\
\hline
\end{tabular}

*Homeopathy significantly superior to placebo $(P<0.05)$.

Reliable evidence.

References

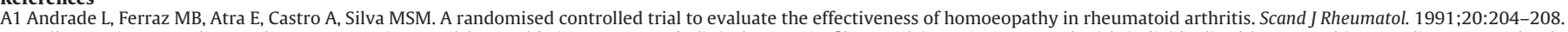

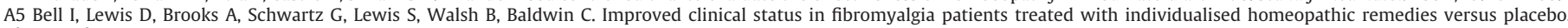
Rheumatology. 2004;43:577-582.

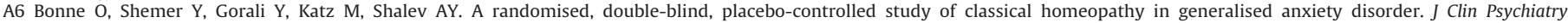
2003;64:282-287.

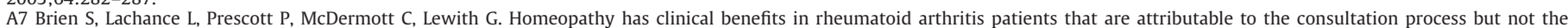
homeopathic remedy: a randomised controlled clinical trial. Rheumatology (Oxford). 2011;50:1070-1082.

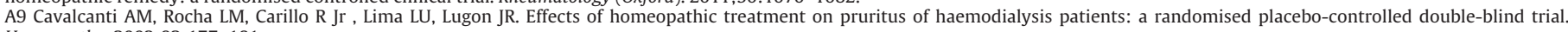
Homeopathy. 2003;92:177-181.

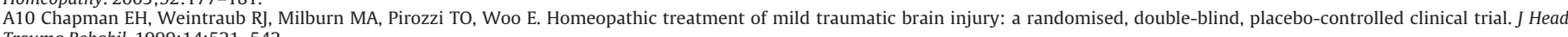
Trauma Rehabil. 1999;14:521-542.

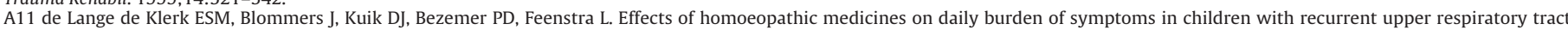
infections. Br Med J. 1994;309:1329-1332.

A13 Fisher P, McCarney R, Hasford C, Vickers A. Evaluation of specific and non-specific effects in homeopathy: Feasibility study for a randomised trial. Homeopathy. 2006;95:215-222.

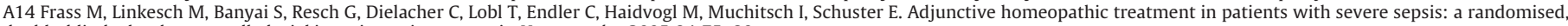
double-blind, placebo-controlled trial in an intensive care unit. Homeopathy. 2005;94:75-80.

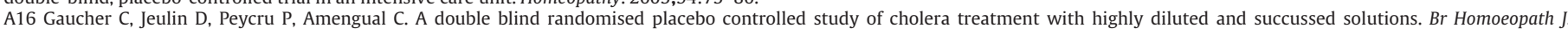
1994;83:132-134.

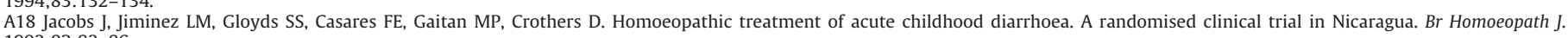
$1993 ; 82: 83-86$

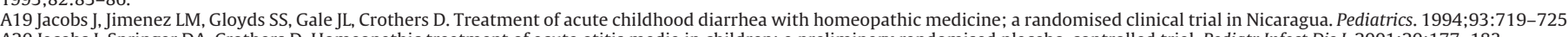
A20 Jacobs J, Springer DA, Crothers D. Homeopathic treatment of acute otitis media in children: a preliminary randomised placebo-controlled trial. Pediatr Infect Dis J. 2001;20:177-183.

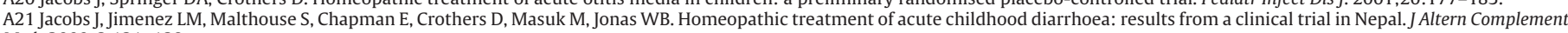
Med; 2000;6:131-139.

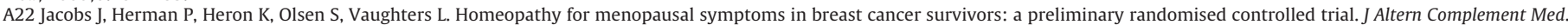
2005b;11:21-27.

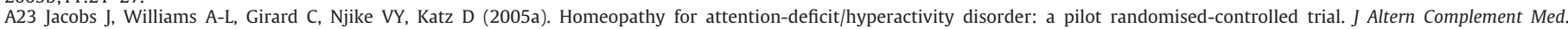
2005a; $11: 799-806$.

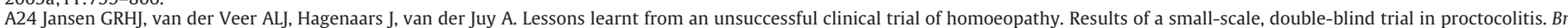
Homoeopath J. 1992;81:132-138.

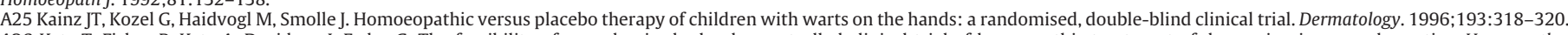

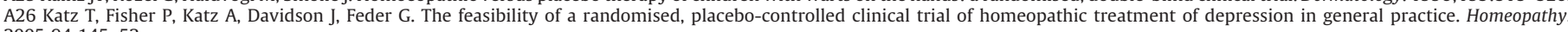
2005;94:145-52.

A30 Naudé DF, Couchman IMS, Maharaj A. Chronic primary insomnia: efficacy of homeopathic simillimum. Homeopathy. 2010;99:63-68. [Published erratum: Homeopathy. 2010;99:151].

A31 Rastogi DP, Singh VP, Singh V, Dey SK, Rao K. Homeopathy in HIV infection: a trial report of double-blind placebo controlled study. Br Homoeopath J. $1999 ; 88: 49-57$.

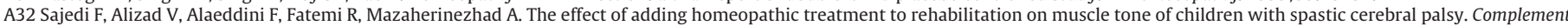
Ther Clin Pract. 2008;14:33-37.

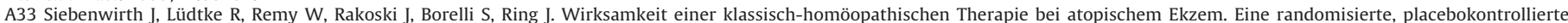

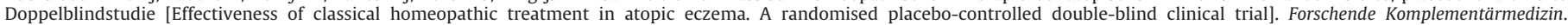
2009;16:315-323.

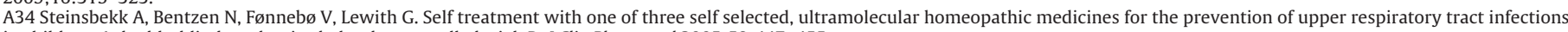
in children. A double-blind randomised placebo controlled trial. Br J Clin Pharmacol 2005;59:447-455.

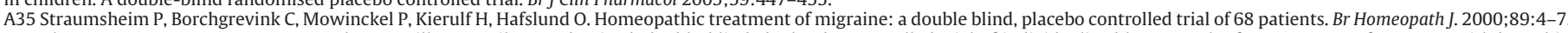

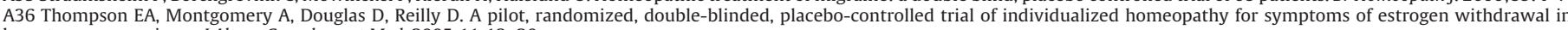
breast-cancer survivors. J Altern Complement Med. 2005;11:13-20.

A37 Walach H, Häusler W, Lowes T, Mussbach D, Schamell U, Springer W, Stritzl G, Haag G. Classical homeopathic treatment of chronic headaches. Cephalalgia. 1997;17:119-126.

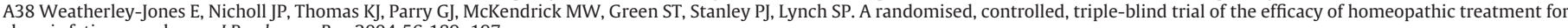
chronic fatigue syndrome. J Psychosom Res. 2004;56:189-197.

A39 White A, Slade P, Hunt C, Hart A, Ernst E. Individualised homeopathy as an adjunct in the treatment of childhood asthma: a randomised placebo controlled trial. Thorax. 2003;58:317-321. A40 Whitmarsh TE, Coleston-Shields DM, Steiner TJ. Double-blind randomized placebo-controlled study of homoeopathic prophylaxis of migraine. Cephalalgia. 1997; 17:600-604.

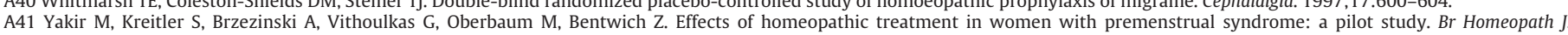
2001;90:148-153. 
Table 3

Frequency Table of MVHT and RoB.

\begin{tabular}{|c|c|c|c|c|c|}
\hline \multirow{2}{*}{\multicolumn{2}{|c|}{ Number of trials }} & \multicolumn{3}{|c|}{ Risk of bias } & \multirow{3}{*}{$\begin{array}{c}\text { Totals } \\
19\end{array}$} \\
\hline & & \multirow{2}{*}{$\frac{\text { Uncertain** }}{3}$} & \multirow{2}{*}{$\frac{\text { Uncertain }}{5}$} & \multirow{2}{*}{$\begin{array}{c}\text { High } \\
11\end{array}$} & \\
\hline \multirow{3}{*}{ MVHT } & Acceptable & & & & \\
\hline & Uncertain & 0 & 3 & 6 & 9 \\
\hline & Inadequate & 0 & 1 & 3 & 4 \\
\hline \multicolumn{2}{|c|}{ Totals } & 3 & 9 & 20 & 32 \\
\hline
\end{tabular}

**Reliable evidence.

Table 4

Frequency table of MVHT and direction of treatment effect.

\begin{tabular}{|c|c|c|c|c|}
\hline \multirow{2}{*}{\multicolumn{2}{|c|}{ Number of trials }} & \multicolumn{2}{|c|}{ Direction of treatment effect } & \multirow{3}{*}{$\begin{array}{c}\text { Totals } \\
16\end{array}$} \\
\hline & & \multirow{2}{*}{$\begin{array}{c}\text { Favours } \\
\text { homeopathy } \\
12\end{array}$} & \multirow{2}{*}{$\begin{array}{c}\begin{array}{c}\text { Favours } \\
\text { placebo }\end{array} \\
4 \\
\end{array}$} & \\
\hline \multirow{3}{*}{ MVHT } & Acceptable & & & \\
\hline & Uncertain & 2 & 3 & 5 \\
\hline & Inadequate & 1 & 0 & 1 \\
\hline \multicolumn{2}{|c|}{ Totals } & 15 & 7 & 22 \\
\hline
\end{tabular}

Table 5

Frequency Table of RoB and direction of treatment effect.

\begin{tabular}{|c|c|c|c|c|}
\hline \multirow{2}{*}{\multicolumn{2}{|c|}{ Number of trials }} & \multicolumn{2}{|c|}{ Direction of treatment effect } & \multirow{3}{*}{$\begin{array}{c}\text { Totals } \\
3\end{array}$} \\
\hline & & \multirow{2}{*}{$\begin{array}{c}\begin{array}{c}\text { Favours } \\
\text { homeopathy }\end{array} \\
3 \\
\end{array}$} & \multirow{2}{*}{$\begin{array}{c}\begin{array}{c}\text { Favours } \\
\text { placebo }\end{array} \\
0 \\
\end{array}$} & \\
\hline \multirow{3}{*}{ RoB } & Uncertain** & & & \\
\hline & Uncertain & 6 & 3 & 9 \\
\hline & High & 6 & 4 & 10 \\
\hline \multicolumn{2}{|c|}{ Totals } & 15 & 7 & 22 \\
\hline
\end{tabular}

** Reliable evidence.

Table 6

Sensitivity analysis by overall quality designation.

\begin{tabular}{|c|c|c|c|c|c|c|c|}
\hline Ref. & First author & Year & Overall designation & OR $[95 \% \mathrm{CI}]$ & $\begin{array}{l}\text { Pooled OR }[95 \% \\
\text { CI] for N trials }\end{array}$ & $\begin{array}{l}\mathrm{N} \text { trials } \\
\text { included }\end{array}$ & $\begin{array}{c}P \text { for } \mathrm{N} \\
\text { trials }\end{array}$ \\
\hline A5 & Bell & 2004 & High quality & $1.77[0.66,4.72]$ & \multirow{3}{*}{$1.98[1.16,3.38]$} & \multirow{3}{*}{3} & \multirow{3}{*}{0.013} \\
\hline A19 & Jacobs & 1994 & High quality & $2.22[1.00,4.94]$ & & & \\
\hline $\mathrm{A} 20$ & Jacobs & 2001 & High quality & $1.84[0.63,5.36]$ & & & \\
\hline A10 & Chapman & 1999 & Moderate quality & $1.98[0.72,5.49]$ & \multirow{8}{*}{$1.64[1.24,2.17]$} & \multirow{8}{*}{11} & \multirow{8}{*}{$<0.001$} \\
\hline A14 & Frass & 2005 & Moderate quality & $3.13[1.10,8.86]$ & & & \\
\hline A23 & Jacobs & $2005 a$ & Moderate quality & $0.80[0.25,2.57]$ & & & \\
\hline A36 & Thompson & 2005 & Moderate quality & $1.94[0.66,5.64]$ & & & \\
\hline A41 & Yakir & 2001 & Moderate quality & $5.50[0.96,31.62]$ & & & \\
\hline A6 & Bonne & 2003 & Moderate quality & $0.87[0.28,2.73]$ & & & \\
\hline A11 & de Lange de Klerk & 1994 & Moderate quality & $1.67[0.96,2.89]$ & & & \\
\hline A35 & Straumsheim & 2000 & Moderate quality & $0.80[0.34,1.90]$ & & & \\
\hline A7 & Brien & 2011 & Low quality & $0.86[0.16,4.47]$ & \multirow{11}{*}{$1.53[1.22,1.91]$} & \multirow{11}{*}{22} & \multirow{11}{*}{$<0.001$} \\
\hline A9 & Cavalcanti & 2003 & Low quality & $3.50[0.55,22.30]$ & & & \\
\hline A13 & Fisher & 2006 & Low quality & $1.33[0.34,5.30]$ & & & \\
\hline A22 & Jacobs & $2005 b$ & Low quality & $3.84[1.06,13.90]$ & & & \\
\hline A31 & Rastogi (a) & 1999 & Low quality & $1.36[0.45,4.10]$ & & & \\
\hline A31 & Rastogi (b) & 1999 & Low quality & $0.53[0.17,1.69]$ & & & \\
\hline A33 & Siebenwirth & 2009 & Low quality & $0.49[0.07,3.65]$ & & & \\
\hline A38 & Weatherley-Jones & 2004 & Low quality & $1.47[0.62,3.47]$ & & & \\
\hline A32 & Sajedi & 2008 & Low quality & $0.55[0.09,3.34]$ & & & \\
\hline $\mathrm{A} 40$ & Whitmarsh & 1997 & Low quality & $1.72[0.69,4.34]$ & & & \\
\hline $\mathrm{A} 25$ & Kainz & 1996 & Low quality & $1.41[0.45,4.45]$ & & & \\
\hline
\end{tabular}

tity of evidence available to answer a given research question. ${ }^{8}$ It is reassuring, at least, that so few of our 32 homeopathy trials have overtly inadequate $\mathrm{MVHT}^{3}$ and that the majority thus seem to involve 'genuine homeopathy'. ${ }^{9}$ It is unknown to what extent model validity might impact on the interpretation of RCT findings in other branches of Complementary/Alternative Medicine (CAM); our MVHT method seems adaptable to addressing that question, as previously proposed. ${ }^{5}$ It is also currently unknown if other potential flaws, connected with deficiencies of external validity for 
example, ${ }^{10}$ might impinge on overall quality ratings of the trials we examined.

In classifying each of MVHT and RoB, we considered some domains of assessment to have lesser importance than others. This judgmental approach to the relative importance of domains is consistent with the Cochrane method of attributing overall RoB per trial. ${ }^{6}$ It preserves PRISMA standards of reporting, and it has successfully identified trials of individualised homeopathy that comprise 'reliable evidence'. Similar dual assessment and analysis will feature in our subsequent systematic review of placebocontrolled RCTs of non-individualised homeopathy.

\section{Conclusions}

The quality appraisal of 32 RCTs of individualised homeopathic treatment, merging the assessments of MVHT and RoB, identified three trials of 'high quality', eight of 'moderate quality', 18 of 'low quality' and three of 'very low quality'. Since the three 'high quality' trials are those that were already identified as 'reliable evidence', there is no change in our main conclusion from previous metaanalysis based on the best-quality RCTs: the medicines prescribed in individualised homeopathy may have small, specific, treatment effects.

\section{Competing interests}

RTM, JC and SM are employed by, or associated with, a homeopathy charity to clarify and extend an evidence base in homeopathy. The study is intrinsic to the charity work of the British Homeopathic Association (BHA) through its Research Development Adviser, RTM; no other member of the BHA's staff, nor its trustees, contributed to the design, analysis or write-up of the work. Each of the following is a former member of the International Scientific Committee for Homeopathic Investigations (ISCHI): RTM, MVW, JJ, MO, JF, RJM, HR, FD, PF. The University of Glasgow was supported by a grant from the British Homeopathic Association. For activities outside the submitted study, JRTD has received honoraria or royalties from a number of organisations, including universities and pharmaceutical companies.

\section{Authors' contributions}

RTM devised and led the study in collaboration with all coauthors. SML, LAL, JC, SM, JRTD and IF are co-authors of the original paper on risk-of-bias ${ }^{2}$; MVW, JJ, MO, JF, RJM, HR, FD and PF are coauthors of the original paper on model validity. ${ }^{3}$ Each co-author contributed to interpretation of the merged data, and edited and approved the final manuscript.

\section{Acknowledgements}

The study was assisted by a grant from the Manchester Homeopathic Clinic to the British Homeopathic Association.

Chi-square and Fisher's Exact tests were carried out by Elizabeth Baitson, British Homeopathic Association.

\section{Appendix A. Supplementary data}

Supplementary data associated with this article can be found, in the online version, at http://dx.doi.org/10.1016/j.ctim.2016.01. 005.

\section{References}

1. Mathie RT, Legg LA, Clausen J, Davidson JRT, Lloyd SM, Ford I. Systematic review and meta-analysis of randomised, placebo-controlled, trials of individualised homeopathic treatment: study protocol. Version 1.0; 25 January 2013. http://www.britishhomeopathic.org/wp-content/uploads/ 2013/05/Study_protocol_for_systematic_review.pdf.

2. Mathie RT, Lloyd SM, Legg LA, et al. Randomised placebo-controlled trials of individualised homeopathic treatment: systematic review and meta-analysis. Syst Rev. 2014;3:142

3. Mathie RT, Van Wassenhoven M, Jacobs J, et al. Model validity of randomised placebo-controlled trials of individualised homeopathic treatment. Homeopathy. 2015; 104: 164-169.

4. Schünemann HJ, Oxman AD, Vist GE, et al., on behalf of the Cochrane Applicability and Recommendations Methods Group. Chapter 12: interpreting results and drawing conclusions. In: Higgins JPT, Green S (Eds.). Cochrane Handbook for Systematic Reviews of Interventions; Version 5.1.0. The Cochrane Collaboration; 2011.

5. Mathie RT, Roniger H, Van Wassenhoven M, et al. Method for appraising model validity of randomised controlled trials of homeopathic treatment: multi-rater concordance study. BMC Med Res Methodol. 2012;12:49.

6. Higgins JPT, Altman DG, Sterne JAC. Chapter 8: assessing risk of bias in included studies. In: Higgins JPT, Green S, eds. Cochrane Handbook for Systematic Reviews of Interventions; Version 5.1.0. The Cochrane Collaboration; 2011.

7. Aust N. Response to Robert T Mathie: 'Assessing the validity of clinical trial data in homeopathy does not require an engineer's tools'. FACT. 2014;19:175.

8. El Dib RP, Atallah AN, Andriolo RB. Mapping the Cochrane evidence for decision making in health care. J Eval Clin Pract. 2007;13:689-692.

9. Aickin M. Commentary on Mathie RT et al. Method for appraising model validity of randomised controlled trials of homeopathic treatment: multi-rater concordance study. BMC Med Res Methodol. 2012;12:240.

10. Bornhöft G, Maxion-Bergemann S, Wolf U, et al. Checklist for the qualitative evaluation of clinical studies with particular focus on external validity and model validity. BMC Med Res Methodol. 2006;6:56. 